\title{
EL POSMODERNISMO: SOCIEDAD Y FAMILIA EN EL SIGLO XXI
}

Asmat Chávez, David

Facultad de Teología Universidad Peruana Unión davidasmat@teologia.edu.pe

Fecha de recepción: Julio 2012 Fecha de aceptación y versión final: Septiembre 2012

El posmodernismo y su influencia es un tema que no debe ser pasado por alto. Sociólogos, antropólogos y la iglesia, han tratado de definirlo. Sin embargo, a pesar de lo complejo de sus postulados se ha logrado una exposición de su filosofía, la cual interactúa muy a fondo con nuestro entorno. En este breve estudio, analizaremos cómo este fenómeno filosófico puede haber influenciado tanto en el pensamiento social, familiar, religioso y también cómo puede estar afectando nuestra fe.

Palabras clave: Posmodernismo, modernismo, narcisismo, hedonismo, familias nucleares, fe y religión. 


\section{Introducción}

Toda sociedad ha venido experimentando cambios en sus hábitos, costumbres y su sistema de valores. Para que esto se dé, debe existir una diferencia muy marcada entre la situación anterior y la actual. ${ }^{1}$ Tales cambios no son solo de mentalidad sino de gustos, modas o costumbres además de nuevos valores y planteamientos sociales. ${ }^{2}$ Ésta es la manera en la que se puede apreciar la transición del modernismo al posmodernismo corriente de pensamiento que ha cambiado nuestra concepción de lo económico, social, familiar y religioso. ${ }^{3}$ El posmodernismo manifestándose como un rechazo al modernismo viene exponiendo un tinte relativista, y hedonista con un impacto tal que ha generado un cambio social, en la concepción de las relaciones de pareja y familia, lo que han generado una crisis de valores. ${ }^{4}$

\section{A.Cruz,Sociología una desmitificación} (Barcelona, España: Editorial CLIE, 2001), 65.

2 Ibíd.

3 D. J. Bosch, Misión en transformación: Cambios de paradigma en la teología de la misión (Grand Rapids, MI: Libros Desafío, 2000), 428.

4 Mario Campuzano, "La postmodernidad y su influencia en los individuos, los conjuntos sociales, la psi-

\section{El enfoque posmodernista}

Definir al posmodernismo puede resultar complicado. Surge desde el último tercio del siglo $X^{5}$, y se hace evidente en su distanciamiento del pensamiento racionalista y de una sociedad de clases, es decir procurar un re-direccionamiento. ${ }^{6}$ En tal sentido el posmodernismo aparece como contrapropuesto a la modernidad y sus ideologías. ${ }^{7}$

Una aspecto adicional que identifica el pensamiento posmoderno es su íntimo vínculo con lo tecnológico (celulares, computadoras, internet, redes sociales, innovaciones tecnológicas y más), ${ }^{8}$ así como un recha-

copatología y el psicoanálisis", Vinculo - Revista do NESME 1, no. 6 (2009), bajo "Del modernismo al posmodernismo", http://redalyc.uaemex.mx/src/inicio/ ArtPdfRed.jsp?iCve=139412684007 (Consultado: 10 de Septiembre, 2012).

5 E. A. Perdomo, "Algunas tensiones metodológicas en la teología evangélica latinoamericana de principios del siglo XXI", vol. I, Kairós 34 (Enero-Junio 2004): 72 .

6 Thomas Barfield, ed. "Posmoderno, posmodernismo", Diccionario de Antropología (Siglo Veintiuno, Editores, 2000), 414.

7 P. A. Deiros, "Posmodernidad", Diccionario hispano-Americano de la misión (Casilla, Argentina: COMIBAM Internacional, 1997).

8 Ibíd. 
zo al uso de la razón y la lógica como único medio de la adquisición de la verdad y del conocimiento, remplazándolo por el uso de las dimensiones afectivas e intuitivas, ${ }^{9}$ procurando a través de esto una búsqueda de un pleno individualismo. ${ }^{10} \mathrm{Campu}$ zano, en tal sentido señala:

Lo central de los cambios posmodernos se manifiesta por el incremento del individualismo con un corte narcisista, hedonista y seductor propio de la época de consumo de masas, con el consecuente aflojamiento de los lazos sociales y los vínculos familiares y de pareja, así como el desplazamiento de ciudadanos a consumidores y el vaciamiento de sentido de muchas instituciones...La libertad queda reducida a la libertad de consumir, no solo de consu-

9 D. Shenk, Demasiado valioso para que se pierda (Wheaton, IL: Alianza Evangelica Mundial WEF 1997), 71.

10 Paulina B. Emanuelli, "Posmodernidad y globalización en los medios masivos de comunicación", Revista latina de comunicación social 4, no. 39 (March 2001): 1-8, bajo "Sociedad, cultura, juventud y valores contemporáneos", https://web.ebscohost.com/ ehost/ detail ? vid $=4 \&$ hid $=110 \&$ sid $=29 \mathrm{e} 162$ ca-6453-49f4-8299-83b310bad38f $\% 40$ sessionmgr $112 \&$ bdata $=$ Jmxhbmc9ZX Mmc210ZT1laG9zdC1saXZl\#db=zbh\& $\mathrm{AN}=34101773$ (consultado: 10 de septiembre, 2012). mir mercancías, sino también diversiones, viajes, servicios, salud, deporte y hasta cultura, a excepción de la cultura crítica. ${ }^{11}$

A pesar de lo expuesto, la evaluación de las propuesta posmodernista, puede gozar de una creciente aceptación. 12 Pero ¿hasta qué punto su inocente aceptación puede ser contraproducente para el sistema familiar y la sociedad? En tal sentido H. F. Bullón parece responder:

...que esta tergiversada valoración de la "libertad del hombre moderno", favorece una "deconstrucción de la ciudadanía”, que contrasta con una sociedad moderna que aparece como depositaria de los valores democráticos y constructivos

11 Campuzano, "La posmodernidad y su influencia en los individuos, los conjuntos sociales, la psicopatología y el psicoanálisis", bajo "Impacto de los cambios sociales y culturales en los individuos y conjuntos sociales", http://redalyc.uaemex.mx/src/inicio/ArtPdfRed. jsp? iCve $=139412684007$ (consultado: 10 septiembre, 2012).

12 Pedro Luís Sotolongo Cotrina, "Posmodernismo y contemporaneidad", ISLAS 43, no. 128 (2001): 127; ver también, Manuel Calviño, "Psicología, marxismo y posmodernismo", Revista cubana de psicología 17, no. 3 (2000): 205-207. 
de ciudadanía. ${ }^{13}$

Tal evaluación sostiene que el problema no es la búsqueda de superación y libertad en sí misma, sino la ambigüedad que el posmodernismo le ha venido imprimiendo a estos conceptos haciéndolos su bandera de presentación, que tiene la tendencia de llevar a la sociedad a un extremo narcisista y hedonista. ${ }^{14}$

\section{Repercusiones posmoder- nistas: sociedad, familia, religión y fe}

Ahora bien, ¿cuán determinante ha venido a ser hoy la incursión del posmodernismo? Hay quienes sostienen que este fenómeno posmoderno no influye tanto en las sociedades conservadoras, pero que sí se evidencia en sociedades desarrolladas ${ }^{15}$ y por qué no en sociedades en vía de desarrollo como la nuestra. Por lo cual señalaremos brevemente las repercusiones del pensamiento posmodernista

13 H. F. Bullón, Misión y desarrollo en América Latina (Buenos Aires, Argentina: Ediciones Kairós, 2000), 20.

14 Ibíd.

15 E. A. Perdomo, "Algunas tensiones metodológicas en la teología evangélica latinoamericana de principios del siglo XXI", 71.

en la sociedad, familia, religión y fe.

\section{Posmodernismo y sociedad}

No puede negarse que la posmodernidad encuentra ventaja en la difusión de su pensamiento por medio de la mass media, tornándose una sociedad de los medios de comunicación. En este sentido Gianni Vattimo argumenta que un evidente aumento en el crecimiento de las masas de comunicación ${ }^{16}$ paradójicamente no permite un conocimiento de la realidad, y es que esta impactante simultaneidad de información no permite una centralidad de pensamiento, por el contrario vemos una pluralidad hasta cierto punto caricaturesca de las realidades, tornándolas subjetivas. ${ }^{17}$ Esto

16 Paulina B. Emanuelli, "Posmodernidad y globalización en los medios masivos de comunicación", bajo "Sociedad, cultura, juventud y valores contemporáneos", https://web.ebscohost. $\operatorname{com} /$ ehost $/$ detail ?vid $=4 \&$ hid $=1$ $10 \&$ sid $=29$ e $162 \mathrm{ca}-6453-49 f 4-8299$ 83b310bad38f\%40 sessionmgr112\&bd ata $=$ Jmxhbmc9ZXMmc210ZT1laG9zd $\mathrm{C} 1 \mathrm{saXZl} \# \mathrm{db}=\mathrm{zbh} \& A \mathrm{~A}=34101773$ (consultado: 10 Septiembre, 2012).

17 Gianni Vattimo, En torno a la posmodernidad (Barcelona: Anthropos Editorial, 2003), 15. 
se debe a que la definición del pensamiento y el análisis de las repercusiones en sociedades anteriores se daban mucho tiempo después de ser expuestas.

Asimismo, se debe agregar un alto sentido de autonomía centralizada en la complacencia propia. Paulina B. Emanuelli percibe que la constitución de una sociedad posmoderna también va contribuyendo a una sociedad superficial (donde predomina la estética, la imagen y la transición), una sociedad emocional (individualidad hedonista y placentera), así como una sociedad más consumista. ${ }^{18}$

Este podría generar un sistema social no muy organizado, dominado por este sentido de interés consumista, no solo de bienes materiales, sino de diversiones, servicios, salud, deporte y cultura (no la crítica). A este fin posmodernista, vienen sirviendo los medios de comunicación. ${ }^{19}$

18 Paulina B. Emanuelli, "Posmodernidad y globalización en los medios masivos de comunicación". (Consultado: el 10 de Septiembre de 2012).

19 Campuzano, "La postmodernidad y su influencia en los individuos, los conjuntos sociales, la psicopatología y el psicoanálisis", bajo "Impacto de los cambios sociales y culturales en los indivi-

\section{La posmodernidad y la familia}

La familia es el núcleo principal que constituye nuestra sociedad, donde se forjan los valores morales e instituciones formales de educación. ${ }^{20}$ Así, ir en pro de la posmodernidad ha generado que se vaya perdiendo ese patrón guía de valores que es regulado por las normas de la familia y la fe, adquiridos como herencia de la religión con su fundamento en la Biblia (Gn 2:18; Éx 20:14; 1 Cor 7:9) y de una sociedad paternalista y conservadora que ya nos dejó. ${ }^{21}$ En tal sentido Habenicht señala que esta sociedad posmoderna no posee un sistema de valores, y que la presión social juega un rol determinante para su desarrollo. ${ }^{22}$ Así también, una sociedad donde Dios no es una necesidad sino una opción, y junto con esa opduos y conjuntos sociales". (Consultado: el 10 de Septiembre de 2012).

20 Román Rodríguez Salón, "Juventud, familia y posmodernidad: (des) estructuración familiar en la sociedad contemporánea". Fermentum. Revista Venezolana de Sociología y Antropología, num. enero-abril (2010): 40.

21 Shenk, 71.

22 Dona J. Habenicht, Diez valores cristianos que todo niño debería conocer (Buenos Aires, Argentina: Asociación casa Editora Sudamericana, 2004), 20. 
ción también sus valores. ${ }^{23}$ Para la sociedad posmoderna de hoy los valores no parten de Dios ni de su palabra sino parten de si mismos, de su Yo rotundo.

En tal sentido en las constitución de las familias del último tercio del siglo XX se viene observando una falta de compromiso de pareja, su baja duración en la unión de sus relaciones, la negativa a un compromiso, ${ }^{24}$ un aumento de familias uniparentales, ${ }^{25}$ contrario al formato de familias nucleares. ${ }^{26}$ Como consecuencia de este proceso de cambio en la estructura de pensamiento socio-familiar, ${ }^{27}$ se ve degradada la autoridad de los padres. En este contexto, la familia sigue existiendo pero no prevalece la unidad familiar, pues la individualidad es la regla y no

\section{Ibíd.}

24 Miguel Ángel Millán, Psicologia y familia (Barcelona: Caritas española, 2002), 265.

25 Puede ser parte de una familia más amplia o familia separada.

26 Solo esta incluido uno de los cónyuges, mayormente la madre. La unidad básica de la organización familiar, compuesta por los cónyuges y sus hijos, puede ser parte de una familia más amplia o familia separada. Millán, 265.

27 José Todoli Luque, "Familia y Sociedad", en Estudios sobre la Familia, ed. (Barcelona: I.T. San Ildefonso, 1981), 99-102. la excepción. ${ }^{28}$ Si en algún instante se concibió el hogar como la primera escuela, hoy los hogares posmodernos no están cumpliendo ese rol, los hijos no quieren ser más alumnos y los padres no asumen su rol de docentes. $^{29}$

En tal sentido Henry Giroux, señala que los jóvenes entre los 18 y 25 años, son considerados como una generación fronteriza que se encuentra en ese período de transición que va creciendo, educándose y re-educándose en medio de un mundo cibernético que va mutando y redefiniendo su concepción de la vida desde un enfoque virtual, destacando ya no tanto el futuro con sus desafíos, sino el ahora. ${ }^{30}$

Sin embargo, Flores vislumbra una esperanza en torno a la

28 Ana Isabel Zermeño Flores, "La Familia en la Génesis del siglo XXI", en Razón y Palabra (2005), bajo "La familia contemporánea", http://www. redalyc.org/src/inicio/ ArtPdfRed. jsp? iCve $=199520623014$ (Consultado: el 11 de Septiembre de 2012).

29 Elena G. White, La educación (Buenos Aires, Asociación Casa Editora Sudamericana, 2000), 20.

30 Henry Giroux, "Educación posmoderna y generación juvenil", Nueva Sociedad, $\mathrm{n}^{\circ} .146$ (1996): 10-12. http://wwww.nuso.org/upload/articulos/2554_1.pdf (consultado: 11 Septiembre, 2012). 
institución de la familia y señala:

Aun cuando hay muchas opciones de vida parece haber una tendencia importante: la gente valora la familia. Quizá no formará la propia pero aprecia el nicho del que proviene o bien, quizá el divorcio deshizo una estructura familiar pero muchas personas divorciadas parecen inclinadas a iniciar otra familia (monogamia sucesiva). La familia parece estar ahí, como alternativa ante un mundo lleno de competencia, de ritmos acelerados, de individualismo, de riesgos, de rupturas. Por un lado parece estar rebasada como respuesta de vida en común de las parejas, pero, por otro, es revalorizada porque representa, junto con la religión (véase que ambas son instituciones primigenias), asideros ante la soledad, los miedos y la incertidumbre. ${ }^{31}$

\section{El posmodernismo, la religión y la fe}

Entiéndase por religión un conjunto de creencias y normas establecido dentro de una

\footnotetext{
31 Ibíd.
}

comunidad de creyentes $^{32}$ y el significado de fe como se deja entender en Heb 11:1, 6, donde la fe es: creer o confiar pero en las promesas de Cristo, donde él viene a ser el objeto de la fe. ${ }^{33}$ Esto vendría a ser un problema desde el enfoque posmoderno ya que una de las premisas que maneja es la desmitificación de la fe, entendiendo por ello el rechazo de todo aquello que no puede ser tangible o que escapa de su propia experiencia sensorial, no permitiéndole ser verdaderamente "cristianos". ${ }^{44}$ Así la fe que se ha de adquirir es desarrollada en la experiencia, tanto relacional como emotiva sin la necesidad de revelación escrita. Tal ideología no solo cambia el concepto de fe que se encuentra en toda la escritura (Ro 10:17) sino que rechaza la autoridad de la misma, ${ }^{35}$ para llevarnos hacia una secularización de la fe.

32 "Religión", Diccionario general de la lengua española Vox (Barcelona: VOX, 1997).

33 S. J. Kistemaker, Comentario al Nuevo Testamento: Hebreos (Grand Rapids, MI: Libros desafío, 1991), 363.

34 P. A. Jiménez, Introducción a los ministerios juveniles (Decatur, GA: Libros AETH, 1997), 18.

35 J. A. León, Tres caminos para conocerse a sí mismo y alcanzar la salud integral (Buenos Aires, Jorge A. León y Rivero, 2002), 20 
Así el posmodernismo, frente a la religión y la fe, ha procurado una búsqueda de la redefinición de creencias, doctrinas, concepción de la organización religiosa, como un pluralismo religioso ${ }^{36}$ (totalmente divagante que va desde el fundamentalismo hasta una religión light). ${ }^{37}$ El posmodernismo rechaza una verdad absoluta (que es Dios) y con ella las normas de fe (sus normas y preceptos) por una vida de confusión sin orden. ${ }^{38}$ De acuerdo a E. A. Perdomo, la religiosidad y la fe se pueden ver grandemente afectadas evidenciándose un sincretismo religioso (la mezcla de lo secular con lo cristiano), el personalismo (una búsqueda de la experiencia religiosa más mística ${ }^{39}$ que racional (Ro 12:1) y una religiosidad ligera/superficial y suave ("light").40

36 Perdomo, E. A. "Hacia una iglesia como institución sierva de los seres humanos", Ed. G. Williams, Kairós 42, (enero-Junio 2008): 40.

37 Carlos Arboleda Mora, "Los alcances de la fe en la posmodernidad", Revista lasallista de investigación 5, no. 2 (2008): 134-135.

38 E. A. Perdomo, "Hacia una iglesia como institución sierva de los seres humanos", 40.

39 Tubert-Oklander, Juan. "Psicoanálisis y religión a la luz de la posmodernidad". Intersticios 14, no. 30 (Enero 2009): 143.

40 Perdomo, "Algunas tensiones
Así el fenómeno posmoderno puede manifestarse de varias maneras como en la teología de la liberación o la teología de la prosperidad, etc. Por ello a diferencia de la modernidad que rechazaba la fe de manera directa, su enfoque religioso con normas, a Dios mismo y su Palabra, el posmodernismo lo recepciona abriéndole una puerta más mística, donde no se encuentra un centro de pensamiento, ni cosmovisión definida. Se unde en el pleno relativismo donde cualquiera puede imponer sus propias opiniones, colocándolos en una situación errante sin sentido, donde solo predomina el "sentirse bien". ${ }^{41}$

\section{Conclusión}

Hemos de reconocer que nos ha tocado vivir en un contexto social de transición (tocante a América Latina), al cual no podemos escapar pues nos rodea bombardeándonos mediante la mass media. Esto nos ha llevado también a considerar su impacto, sino directo, colateral en la

metodológicas", 73.

41 Norman Gullley, ¡Cristo Viene! Un enfoque cristocéntrico de los eventos delos últimos días (Buenos Aires, Asociación Casa Editora Sudamericana, 1998), 29-36 
institución de la familia, en la cual ha generado un cambio de paradigmas donde el relativismo, la individualidad se hacen claros, afectando su sistema de creencias y valores. Sin embargo, esto nos debe llevar a analizar, estudiar y valorar la manera en la que constituye y viene constituyendo nuestra religión, fe y familia los cuales funcionan como un ente regulador y estabilizador de la sociedad. 